\title{
Pain, distress, and anticipated recovery for older versus younger emergency department patients after motor vehicle collision
}

Gregory F Pereira', Samuel A McLeann ${ }^{2,3}$, Thomas J Tkacik², Robert A Swor ${ }^{4}$, Jeffrey S Jones ${ }^{5}$, David C Lee ${ }^{6}$, David A Peak ${ }^{7}$, Robert M Domeier ${ }^{8}$, Niels K Rathlev ${ }^{9}$, Phyllis L Hendry ${ }^{10}$ and Timothy F Platts-Mills ${ }^{2,3^{*}}$

\begin{abstract}
Background: Motor vehicle collisions (MVCs) are the second most common injury mechanism resulting in emergency department (ED) visits by older adults. MVCs result in substantial pain and psychological distress among younger individuals, but little is known about the occurrence of these symptoms in older individuals. We describe the frequency of and characteristics associated with pain, distress, and anticipated time for physical and emotional recovery for older adults presenting to the ED after MVC in comparison to younger adults.

Methods: In-person interviews were conducted for adults presenting to one of eight EDs after MVC without an obvious fracture or injury requiring admission as part of two prospective studies. Pain severity was assessed using a 0-10 verbal scale. Distress was assessed using the Peritraumatic Distress Inventory (range 0-52). Patients were asked to estimate their expected time for physical and emotional recovery; these responses were dichotomized to $<30$ or $\geq 30$ days. ED pain and distress and associations between patient and collision characteristics and ED pain and distress were examined for patients age 65 years and older and patients age 18 to 64.

Results: Older $(n=96)$ and younger $(n=943)$ adults had the same mean pain scores (5.5, SD 2.5 vs. 5.5, SD 2.4). Distress scores were lower in older than in younger adults (15.5, SD 9 vs. 19.2, SD 10). A higher percentage of older adults than younger adults had an anticipated time to physical recovery $\geq 30$ days (41\%, 95\% confidence interval [Cl] 28\%-55\% vs. $11 \%, 95 \% \mathrm{Cl} 9 \%-13 \%)$. Similarly, older adults were more likely to have an anticipated time for emotional recovery $\geq 30$ days (45\%, 95\% Cl 35\%-55\% vs. 17\%, 95\% Cl 15\%-20\%). Older adults were less likely than younger adults to have moderate or severe neck pain (score $\geq 4)(25 \%, 95 \%$ Cl $23 \%$ to $41 \%$ vs. $54 \%, 95 \% \mathrm{Cl} 48 \%$ to $60 \%$ ) or back pain $(31 \%, 95 \%$ $\mathrm{Cl} 23 \%$ to $46 \%$ vs. $56 \%, 95 \% \mathrm{Cl} 51$ to $62 \%$ ) but more likely to have moderate or severe chest pain (42\%, 95\% Cl 32\% to $50 \%$ vs. 20\%, 95\% Cl 16 to 23\%). Pre-MVC depressive symptoms and pain catastrophizing were positively associated with pain and distress in both older and younger adults.

Conclusions: In our cohort, older adults who presented to the ED after MVC experienced similar pain severity as younger patients and less distress but were more likely to estimate their times for physical and emotional recovery to be 30 days or more. Increased emergency provider awareness of acute pain and distress symptoms among older patients experiencing MVC may improve outcomes for these patients.
\end{abstract}

Keywords: Geriatrics, Pain, Emergency medicine, Traffic accidents

\footnotetext{
* Correspondence: tplattsm@med.unc.edu

${ }^{2}$ Department of Anesthesiology, University of North Carolina, 101 Manning Drive, CB \#7010, Chapel Hill, NC 27599-7010, USA

${ }^{3}$ Departments of Emergency Medicine and Anesthesiology, University of North

Carolina, 101 Manning Drive, CB \#7010, Chapel Hill, NC 27599-7010, USA

Full list of author information is available at the end of the article
}

\section{Biomed Central}

(c) 2014 Pereira et al.; licensee BioMed Central. This is an Open Access article distributed under the terms of the Creative Commons Attribution License (http://creativecommons.org/licenses/by/2.0), which permits unrestricted use, distribution, and reproduction in any medium, provided the original work is properly credited. The Creative Commons Public Domain Dedication waiver (http://creativecommons.org/publicdomain/zero/1.0/) applies to the data made available in this article, unless otherwise stated. 


\section{Background}

Adults age 65 years and older make an estimated 250,000 US emergency department (ED) visits each year for evaluation after motor vehicle collision (MVC), making this the second most common cause of injury resulting in ED visits for this age group [1,2]. The number of older adults experiencing an MVC is anticipated to double between 2010 and 2030 [3]. Prolonged hospital stays and high mortality rates have been described for older adults experiencing injuries requiring admission after MVC [4-6], and high rates of acute pain and distress have been described for individuals of all ages with severe injuries $[7,8]$. However, $80 \%$ of older adults who present to the ED after MVC are discharged to home after evaluation [9], and outcomes for these patients have received little study.

Among younger adult MVC patients who are discharged to home after ED evaluation, acute pain and distress symptoms are common [10]. These symptoms cause substantial suffering, and are also important predictors of persistent pain and psychological sequelae after MVC, which constitute an important post-injury public health problem [11]. While the epidemiology of acute pain and psychological symptoms has been described in younger adults, initial pain and psychological symptoms in older adults presenting to the ED after MVC have not been well characterized. Understanding age-related differences in acute pain and psychological symptoms following MVC has the potential to help providers anticipate the types and severity of problems older patients experience after MVC. In addition, examining associations between patient age, acute pain, and psychological symptoms may provide insights into the mechanisms underlying the initial response to injury across the lifespan and the influence of this response on the development of persistent post-MVC, which is a major public health problem in developed countries [11]. Early analgesic treatment and education regarding movement and pain-relief can improve outcomes after MVC [12,13], but further work is needed to identify high risk patients and to understand mechanisms leading to persistent pain and psychological sequelae.

The objective of this study is to compare pain, distress symptoms, and recovery expectations between older and younger adults who present to the ED after MVC and are discharged to home, and to examine associations between patient and collision characteristics and pain and distress symptoms for these two age groups.

\section{Methods}

\section{Study design and setting}

We analyzed cross-sectional data obtained as part of two prospective cohort studies of patients evaluated in the ED following MVC. The two studies, European American CRASH (EA CRASH) and Older Adult CRASH (OA
CRASH), each enrolled patients from the same eight EDs in four no-fault insurance states (Michigan, Massachusetts, New York and Florida), where litigation associated with MVC is relatively uncommon. Details of the methods for EA CRASH have been reported [14]. A summary of the methods and differences between the two cohorts is presented below. Each study was approved by the Institutional Review Boards of the coordinating institution (University of North Carolina) and all participating hospitals (William Beaumont Health System, Spectrum Health System. North Shore University Hospital, Massachusetts General Hospital, St. Joseph Mercy Hospital, Baystate Medical Center, University of Florida Health System), and each participant provided written informed consent.

\section{Selection of participants}

Patients who presented to the ED within 24 hours of an MVC with injuries unlikely to require admission were screened for eligibility. EA CRASH enrollment was limited to non-Hispanic European American adults age 18 to 65 years. Exclusions based on self-reported race and ethnicity were made in EA CRASH in order to prevent population stratification bias associated with genetic analyses performed as part of the study [15]. OA CRASH included individuals of all races and ethnicities age 65 years and older. In both studies, patients were excluded if they were unable to read and understand English, were not alert and oriented, had fractures that were evident at the time of the ED assessment by the research assistant, intracranial injury, laceration with significant hemorrhage, or other injuries considered life-threatening or likely to require hospital admission as judged by the treating physician at the time of RA assessment. In OA CRASH, patients were also excluded if they had cognitive impairment as defined by a Six-Item Screener score less than four [16]. In the study of younger adults (EA $\mathrm{CRASH}$ ), patients taking a $\beta$-receptor antagonist or taking daily opioids were also excluded. During the five months for which recruitment to EA CRASH and OA CRASH overlapped at the eight study sites, patients age 65 years were first assessed for enrollment in EA CRASH. In order to define comparable older and younger groups of participants, we excluded from analysis OA CRASH patients who were non-white or Hispanic. Patients 65 years of age who were enrolled in the EA CRASH study $(n=5)$ were categorized as age 65 years and older and analyzed with OA CRASH patients (Figure 1).

\section{Measures}

Study participants were interviewed by trained research assistants in the ED using a standardized questionnaire with explicit definitions of study variables. These interviews assessed sociodemographic and crash characteristics, pain, 


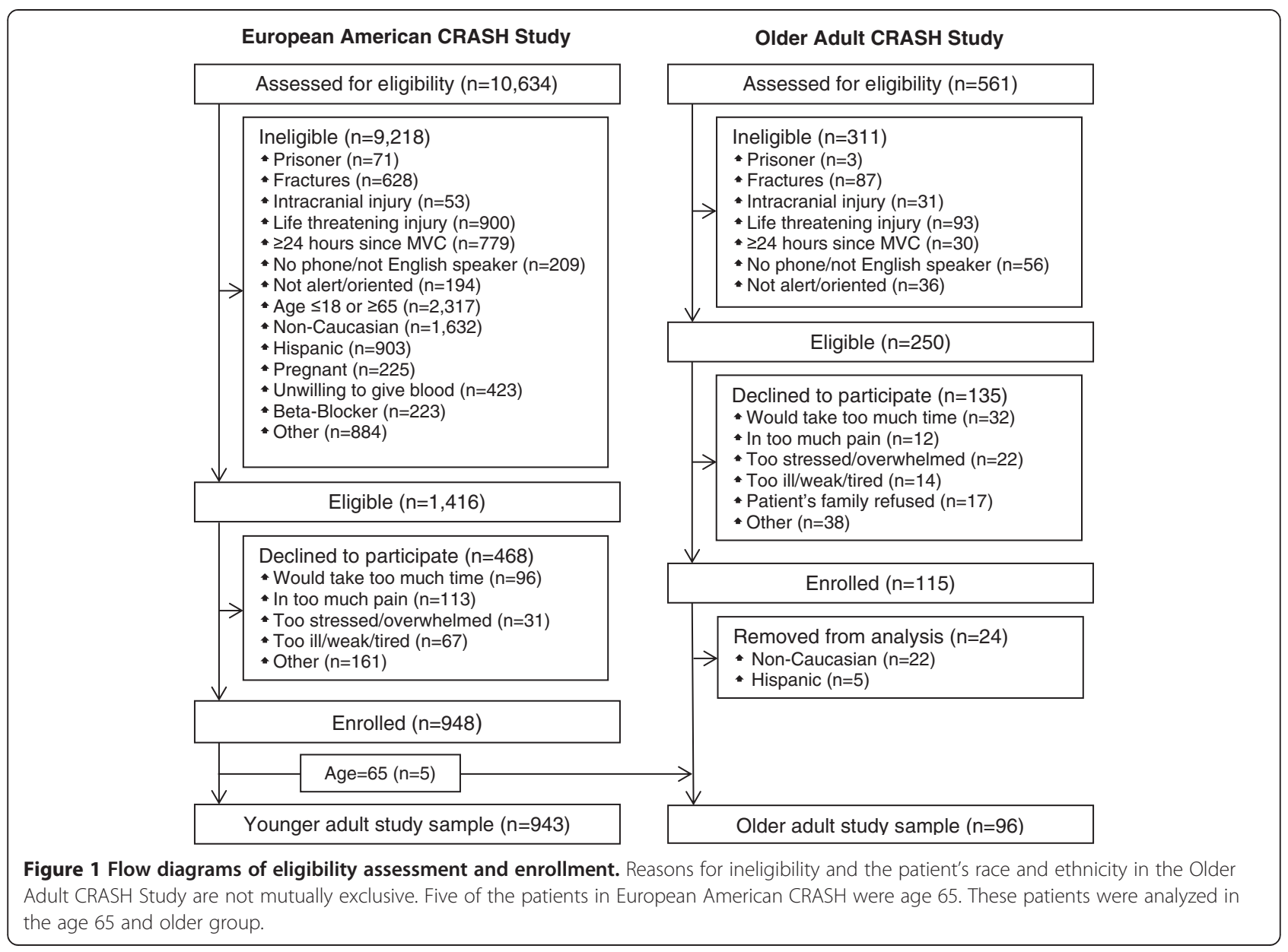

and psychological symptoms (e.g., distress) and traits (e.g., pain catastrophizing, depressive symptoms). The severity of motor vehicle damage was rated by study participants as minor, moderate, or severe, with severe damage defined as the vehicle not being drivable. Agreement between ED patient descriptions of the severity of vehicle damage and police reports have previously been described [17]. Pain severity in the ED and average pain in the past month were assessed using a 0 to 10 verbal scale. Distress was assessed using the Peritraumatic Distress Inventory, a 13-item measure intended to assess distress in the early aftermath of trauma [18]. Anticipated time to physical recovery and anticipated time to emotional recovery were assessed in days. Pain catastrophizing, defined as cognitive and emotional responses to pain characterized by magnification of pain, rumination on pain, and feelings of helplessness in response to pain, was assessed using the 13-item Pain Catastrophizing Scale [19]. Pain catastrophizing was dichotomized based on a Pain Catastrophizing Score of $\geq 10$ (range 0-52); this score represented the $75^{\text {th }}$ percentile of scores for the entire cohort.
In the study of younger adults, depressive symptoms were measured using the 20-item Center for Epidemiologic Studies Depression Scale-Revised (CES-D-20) [20]. In the study of older adults, depressive symptoms was measured using a 10-item version of the Center for Epidemiologic Studies Depression Scale (CES-D-10) adapted specifically for older adults $(n=41)$ [21]) or a two item measure of depression which assesses dysthymia and anhedonia symptoms $(n=50)$ [22]. Agreements between each of the three instruments used to assess for the presence of depressive symptoms and a criterion standard diagnosis of depression established using the National Institute of Mental Health Diagnostic Interview Schedule have been described [23]. The presence of depressive symptoms was determined based on previously reported cutoffs for each of the three measures used: $\geq 16$ for the CES-D-20 measure (range 0-60) [20]; $\geq 4$ for the CES-D-10 score (range 0-10) [21]; or a yes to either question from the two-item instrument [22]. Use of diagnostic imaging tests, diagnosis of fractures, and disposition from the ED (i.e. discharged, observed, or admitted) were ascertained by 
research assistants from each study site during the week following the ED visit. Details of the data extraction process have been published [14] and were the same for both studies.

\section{Data analysis}

Sociodemographic characteristics of participants age 65 years and older (older adults) and those age 18 to 64 years (younger adults) were summarized using proportions for categorical variables and means and standard deviations for continuous variables. Anticipated times to physical and emotional recovery were non-normally distributed. Most patients anticipated that they would recover in the first 14 days; a second cluster of patients anticipated physical and emotional recovery $\geq 30$ days. Based on this distribution, anticipated times to physical and emotional recovery were dichotomized into less than 30 days vs. 30 days or more. Pain scores and distress symptom scores among subgroups of patients defined by sociodemographic, psychological, and collision characteristics are reported as means and associated 95\% confidence intervals separately for older and younger adults. The extent to which associations between patient characteristics and outcomes differed between younger and older adults was tested using linear regression models including variables for 1) age group, 2) the patient or collision characteristic, and 3) a term for the interaction between the age group and the patient or collision characteristic. A p-value $<0.05$ for the interaction term was defined as indicating a statistically significant interaction, indicating that the relationship between the characteristic and the outcome was different for younger vs. older adults. All available data were used for analyses, and no sample size calculation was performed. Analyses were conducted using Stata IC 11.0 (StataCorp LP, College Station, Texas).

\section{Results}

The EA CRASH study screened 10,634 adults between February 2009 and October 2011; OA CRASH screened 561 adults between June 2011 and March 2013. From these two studies, 948 adults from EA CRASH and 91 adults from OA CRASH met eligibility criteria, consented to participation, and met subsequent criteria for these analyses (Figure 1). After reclassifying 5 patients age 65 years from EA CRASH as older adults, analyses were then conducted on 943 individuals age 18 to 64 years and 96 individuals age 65 years or older.

Relative to younger adults, older adults had less formal education, worse self-rated health, and were more likely to report pain during the month prior to the MVC (Table 1). The majority of older and younger patients were drivers, wore seat belts, and reported moderate or severe vehicle damage. Older adults were more likely to report airbag deployment, likely because they were more often involved in head-on or side-impact collisions. Older adults were also more likely to be transported by ambulance, and to report a greater sense of life threat

Table 1 Characteristics of patients presenting to the emergency department after motor vehicle collision, by age group (years)

\begin{tabular}{|c|c|c|}
\hline \multirow[t]{2}{*}{ Characteristic } & \multirow{2}{*}{$\begin{array}{l}\text { Age } 18-64 \\
N=943\end{array}$} & \multirow{2}{*}{$\begin{array}{l}\text { Age } \geq 65 \\
N=96\end{array}$} \\
\hline & & \\
\hline Age, mean (SD), years & $35(13)$ & $72(6)$ \\
\hline Female, \% & 60 & 52 \\
\hline \multicolumn{3}{|l|}{ Education, \% } \\
\hline 8-11 years & 4 & 12 \\
\hline High school & 19 & 21 \\
\hline Post high school* & 39 & 29 \\
\hline College graduate & 25 & 20 \\
\hline Post graduate & 12 & 18 \\
\hline \multicolumn{3}{|l|}{ General health, \% } \\
\hline Excellent & 31 & 18 \\
\hline Very good & 41 & 34 \\
\hline Good & 22 & 29 \\
\hline Fair & 7 & 16 \\
\hline Poor & 1 & 3 \\
\hline \multicolumn{3}{|l|}{ Average pain past month, $\%$} \\
\hline None $(0)$ & 65 & 44 \\
\hline Mild (1-3) & 15 & 24 \\
\hline Moderate (4-6) & 12 & 17 \\
\hline Severe $(6+)$ & 9 & 16 \\
\hline$\geq 4$ drinks per week, $\%$ & 39 & 17 \\
\hline Pain catastrophizing, \% & 44 & 33 \\
\hline Depressive symptoms, \% & 20 & 25 \\
\hline Driver, \% & 86 & 84 \\
\hline Seat-belt, \% & 90 & 93 \\
\hline \multicolumn{3}{|l|}{ Collision type $^{\dagger}, \%$} \\
\hline Head-on & 57 & 48 \\
\hline Side-impact & 34 & 44 \\
\hline Rear-ended & 36 & 27 \\
\hline Air bags deployed, \% & 29 & 53 \\
\hline \multicolumn{3}{|l|}{ Damage severity, \% } \\
\hline Minor & 14 & 13 \\
\hline Moderate & 31 & 48 \\
\hline Severe & 55 & 39 \\
\hline Life threat ${ }^{\ddagger}(0-10)$, mean (SD) & $4.2(3.1)$ & $4.9(3.6)$ \\
\hline Arrived by ambulance, \% & 58 & 88 \\
\hline
\end{tabular}

*Includes technical schools and college without graduation. ${ }^{\dagger}$ Not mutually exclusive.

${ }^{*}$ How life threatening was your motor vehicle accident? 
during the collision. Computed tomography was used more often than plain radiography to image the cervical spine in older adults (Table 2). Overall, plain radiographs and computed tomography scans were both performed more frequently for older adults than younger adults. Clinically apparent fractures were exclusion criteria for both studies; the diagnosis of fractures after enrollment was more common among older than younger adults, but occurred in less than ten percent of adults in both groups. Older adults were more likely than younger adults to be admitted (13\% vs. $1 \%)$ or observed ( $8 \%$ vs. $1 \%)$ than younger adults.

Mean pain scores in older and younger adults were identical (Table 3). Moderate or severe pain in one or more body region was reported by $77 \%$ ( $95 \%$ confidence interval [CI], $67 \%$ to $84 \%$ ) of older adults and $80 \%(95 \%$ CI, $77 \%$ to $82 \%$ ) of younger adults. Both older and younger patients reported a median of 3 (IQR 2-5) body regions with pain (pain score $\geq 1$ ). The distribution of body regions with pain differed between older and younger adults. Moderate or severe chest pain was reported by $42 \%$ ( $95 \% \mathrm{CI}, 20 \%$ to $38 \%$ ) of older adults compared to $20 \%$ (95\% CI, $17 \%$ to $22 \%$ ) of younger adults (Figure 2). In contrast, neck and back pain were reported by $25 \%$

Table 2 Radiographic imaging use, fractures, and disposition, by age group

\begin{tabular}{lll}
\hline Event & Age 18-64 & Age $\mathbf{2 6 5}$ \\
& $\mathbf{N}=\mathbf{9 4 3}$ & $\mathbf{N}=\mathbf{9 6}$ \\
\hline Plain radiography & 27 & 6 \\
Cervical spine, \% & 32 & 43 \\
Chest, \% & 9 & 14 \\
Pelvis, \% & $1.2(1.1)$ & $1.6(1.1)$ \\
Total radiographs, mean(SD) & & \\
Computed tomography (CT) scans & 24 & 45 \\
Head, \% & 23 & 36 \\
Cervical spine, \% & 5 & 19 \\
Chest, \% & 8 & 17 \\
Abdomen/pelvis, \% & $0.7(1.0)$ & $1.4(1.4)$ \\
Total CT scans, mean(SD) & & \\
Fractures, \% & 0 & $2^{*}$ \\
Spine & $<1$ & 3 \\
Rib & $<1$ & 2 \\
Sternum & 1 & 13 \\
Other & $<1$ & \\
Disposition, \% & & 79 \\
Discharged & 98 & \\
Observation & 1 & \\
Admitted & & \\
\hline
\end{tabular}

*Includes one patient with a compression deformity of the sixth thoracic vertebrae the age of which was unknown.
(95\% CI, $17 \%$ to $34 \%$ ) and $31 \%$ (95\% CI, $23 \%$ to $41 \%$ ) of older adults, respectively, compared to $54 \%$ (95\% CI, $50 \%$ to $57 \%$ ) and $56 \%$ (95\% CI, $53 \%$ to $60 \%$ ) of younger adults, respectively.

Mean distress scores were slightly lower in older adults than in younger adults $(15.5,95 \%$ CI 14 to 17 vs. 19.2, $95 \%$ CI 19 to 20). However, the prevalence of substantial distress (distress score $\geq 13$ [24]) was nevertheless high in both groups, with half of older adults and $68 \%$ of younger adults experiencing substantial distress. A higher percentage of older adults than younger adults reported an anticipated time to physical recovery of 30 days or more $(41 \%, 95 \%$ CI $28 \%-55 \%$ vs. $11 \%, 95 \%$ CI 9\%-13\%). Similarly, a higher percentage of older adults reported an anticipated time for emotional recovery of 30 days or more $(45 \%, 95 \%$ CI $35 \%-55 \%$ vs. $17 \%, 95 \%$ CI $15 \%-20 \%)$.

Among younger adults, females and those with less formal education had higher rates of pain and distress (Tables 4,5). Trends in these relationships were also observed among older adults. For both younger and older adults, patients with higher reported pre-MVC depressive symptoms and higher pain catastrophizing in the ED had higher mean pain and distress scores than those that did not. Younger adults who were not rear-ended had higher distress scores than those who were rearended; this association was not observed in older adults. This interaction between age category and rear-end collision on the outcome of distress was statistically significant $(\mathrm{p}<0.01)$; no other interactions between age category and the characteristics examined in Tables 4 and 5 were statistically significant or were suggested by visual inspection of the results.

Sensitivity analyses were conducted in which the sample of older adults was further restricted in order to make them more similar to the younger cohort. Among the subset of older adults who were not taking daily opioids prior to the collision, did not have a fracture, and were discharged home $(n=68)$, the mean pain score (5.1, 95\% CI 4.5 to 5.7) and mean distress score (12.9, 95\% CI 10.6 to 15.2 ) were similar to scores for the overall sample of older adults. Comparisons between these scores and scores for younger patients did not change the overall findings that older patients had similar pain scores, lower distress scores, and were more likely to have an anticipated time for physical recovery or emotional recovery of 30 days or more when compared to younger adults.

\section{Limitations}

We compare results from two studies with minor differences in inclusion and exclusion criteria and assessment measures. In the study of younger adults, $5 \%$ of patients were excluded because they were unwilling to provide a 
Table 3 Pain, distress, and anticipated recovery after motor vehicle collision, by age group

\begin{tabular}{|c|c|c|c|c|c|c|}
\hline \multirow[b]{2}{*}{ Characteristic } & \multicolumn{3}{|l|}{ Age 18-64 } & \multicolumn{3}{|l|}{ Age $\geq 65$} \\
\hline & $N=943$ & & & $N=96$ & & \\
\hline Pain severity, mean $(95 \% \mathrm{Cl})$ & & 5.5 & $(5.3-5.7)$ & & 5.5 & $(5.0-6.0)$ \\
\hline Distress, mean $(95 \% \mathrm{Cl})^{*}$ & 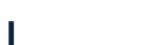 & 19 & $(19-20)$ & & 16 & $(14-17)$ \\
\hline $\begin{array}{l}\text { Anticipated time for physical } \\
\text { recovery } \geq 30 \text { days, } \%(95 \% \mathrm{Cl})^{\dagger}\end{array}$ & 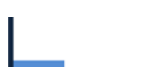 & 11 & $(9-13)$ & & 41 & $(28-55)$ \\
\hline $\begin{array}{l}\text { Anticipated time for emotional } \\
\text { recovery } \geq 30 \text { days, } \%(95 \% \mathrm{Cl})\end{array}$ & $\mathbf{I}$ & 17 & $(15-20)$ & & 45 & $(35-55)$ \\
\hline
\end{tabular}

*Distress measured using the Peritraumatic Distress Inventory scale.

${ }^{\dagger} \mathrm{N}=51$ for patients age $\geq 65$. Mark on $\mathrm{X}$-axis of each histogram indicates 30 days.

blood sample; this was not an exclusion criterion for the older sample. The OA CRASH study used different instruments for assessing depressive symptoms than EA CRASH. Although the accuracies of each of these three instruments for identifying depressive symptoms when compared to a criterion standard diagnosis of depression is good or excellent (area under ROC $>0.8$ for each of the three measures vs. criteria standard [23]), it is possible that the use of different measures caused different estimates for the frequency of depression or associations between depression and pain and distress for older vs. younger adults.

Only $67 \%$ and $46 \%$ of eligible patients participated in the EA CRASH and OA CRASH studies, respectively. Among eligible patients, reasons for non-participation were similar for younger and older adults. For both studies, some patients declined to participate because they were either in too much pain, were too overwhelmed or stressed, or were too weak, ill, or tired. The total number of patients who decline participation for any of these reasons was $15 \%$ of eligible patients in the EA CRASH study and $19 \%$ of eligible patients in the OA CRASH. Non-enrollment of these and other patients likely creates some selection bias, but whether selection bias due to eligible patients declining to participate results in

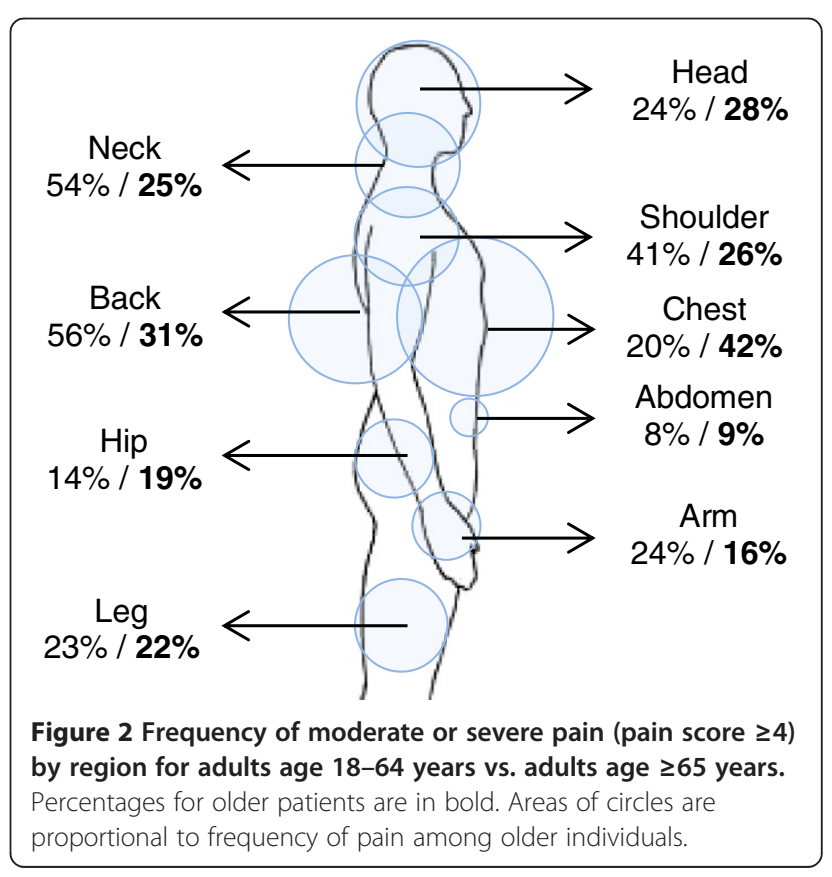


Table 4 Mean emergency department pain scores (0-10 scale) for younger and older adults by patient and collision characteristics

\begin{tabular}{|c|c|c|c|c|}
\hline \multirow[b]{2}{*}{ Characteristic } & \multicolumn{2}{|c|}{ Age 18-64 } & \multicolumn{2}{|c|}{ Age $\geq 65$} \\
\hline & $\mathrm{N}$ & Mean $(95 \% \mathrm{Cl})$ & $\mathrm{N}$ & Mean $(95 \% \mathrm{Cl})$ \\
\hline \multicolumn{5}{|l|}{ Sex } \\
\hline Female & 565 & $5.7(5.5,5.9)$ & 52 & $5.6(4.9,6.3)$ \\
\hline Male & 369 & $5.3(5.0,5.5)$ & 44 & $5.4(4.6,6.3)$ \\
\hline \multicolumn{5}{|l|}{ Education } \\
\hline $8-11$ years & 42 & $7.1(6.3,7.9)$ & 11 & $6.2(4.6,7.8)$ \\
\hline High school & 180 & $5.8(5.5,6.1)$ & 20 & $5.4(4.3,6.4)$ \\
\hline Post high school & 365 & $5.9(5.7,6.1)$ & 28 & $6.2(5.1,7.2)$ \\
\hline College grad & 234 & $5.0(4.7,5.3)$ & 29 & $5.5(4.5,6.4)$ \\
\hline Post grad & 111 & $4.4(4.0,4.8)$ & 17 & $4.3(3.2,5.4)$ \\
\hline \multicolumn{5}{|c|}{ Pain catastrophizing } \\
\hline Yes & 409 & $6.1(5.9,6.3)$ & 31 & $6.4(5.5,7.2)$ \\
\hline No & 513 & $5.1(4.9,5.3)$ & 63 & $5.1(4.4,5.7)$ \\
\hline \multicolumn{5}{|c|}{ Depressive symptoms } \\
\hline Yes & 191 & $6.0(5.6,6.3)$ & 22 & $6.5(5.6,7.5)$ \\
\hline No & 741 & $5.4(5.2,5.6)$ & 68 & $5.0(4.4,5.6)$ \\
\hline \multicolumn{5}{|l|}{ Driver } \\
\hline Yes & 801 & $5.5(5.3-5.6)$ & 79 & $5.4(4.8,5.9)$ \\
\hline No & 133 & $5.9(5.5-6.3)$ & 15 & $6.1(4.5,7.8)$ \\
\hline \multicolumn{5}{|l|}{ Rear-ended } \\
\hline Yes & 334 & $5.5(5.2,5.8)$ & 26 & $5.6(4.6,6.5)$ \\
\hline No & 600 & $5.6(5.4,5.7)$ & 68 & $5.5(4.8,6.1)$ \\
\hline \multicolumn{5}{|l|}{ Damage severity } \\
\hline Severe & 500 & $5.5(5.3,5.7)$ & 35 & $5.3(4.5,6.1)$ \\
\hline Moderate & 276 & $5.6(5.3,5.9)$ & 43 & $5.7(5.0,6.5)$ \\
\hline No or minor & 127 & $5.2(4.7,5.6)$ & 11 & $4.2(2.6,5.8)$ \\
\hline
\end{tabular}

over- or under-estimates of pain and distress symptoms is unknown. Also, only non-Hispanic Caucasian patients were enrolled in EA CRASH, and the analysis of participants in OA CRASH was restricted to non-Hispanic Caucasians. The experiences of pain and distress and the effect of age on these experiences may be different in other racial and ethnic groups [25].

\section{Discussion}

Adults age 65 and older are a growing injury population [26-28], but the types of problems faced by older adults after common injury mechanisms have not been well characterized. In this prospective study of adults presenting to the ED with minor injuries due to MVC, we observed that acute pain was as much a problem for older adults as for younger adults, with more than $75 \%$
Table 5 Mean emergency department distress scores (0-52 scale) for younger and older adults by patient and collision characteristics

\begin{tabular}{|c|c|c|c|c|}
\hline \multirow[b]{2}{*}{ Characteristic } & \multicolumn{2}{|c|}{ Age 18-64 } & \multicolumn{2}{|c|}{ Age $\geq 65$} \\
\hline & $\mathrm{N}$ & Mean $(95 \% \mathrm{Cl})$ & $\mathrm{N}$ & Mean $(95 \% \mathrm{Cl})$ \\
\hline \multicolumn{5}{|l|}{ Sex } \\
\hline Female & 560 & $21.1(20.3,21.9)$ & 52 & $16.9(14.5,19.3)$ \\
\hline Male & 369 & $16.3(15.3,17.2)$ & 44 & $13.9(11.2,16.7)$ \\
\hline \multicolumn{5}{|l|}{ Education } \\
\hline 8-11 years & 42 & $24.4(21.3,27.5)$ & 11 & $17.4(11.9,22.9)$ \\
\hline High school & 178 & $20.2(18.8,21.7)$ & 20 & $14.0(9.65,18.4)$ \\
\hline Post high school & 360 & $19.9(18.9,20.9)$ & 28 & $15.8(12.4,19.2)$ \\
\hline College grad & 235 & $17.6(16.3,18.9)$ & 29 & $17.5(13.6,21.5)$ \\
\hline Post grad & 112 & $16.9(15.3,18.5)$ & 17 & $13.0(9.6,16.5)$ \\
\hline \multicolumn{5}{|c|}{ Pain catastrophizing } \\
\hline Yes & 408 & $22.0(21.2,23.0)$ & 32 & $19.9(17.0,22.7)$ \\
\hline No & 510 & $16.8(16.0,17.7)$ & 64 & $13.4(11.2,15.5)$ \\
\hline \multicolumn{5}{|c|}{ Depressive symptoms } \\
\hline Yes & 190 & $22.7(21.2,24.2)$ & 23 & $18.9(15.8,21.9)$ \\
\hline No & 737 & $18.3(17.6,19.0)$ & 69 & $14.1(11.9,16.2)$ \\
\hline \multicolumn{5}{|l|}{ Driver } \\
\hline Yes & 801 & $19.4(18.7,20.1)$ & 79 & $15.3(13.3,17.3)$ \\
\hline No & 133 & $17.7(16.0,19.4)$ & 15 & $16.8(12.3,21.3)$ \\
\hline \multicolumn{5}{|l|}{ Rear-ended } \\
\hline Yes & 337 & $17.0(16.0,18.0)$ & 26 & $17.5(13.5,21.5)$ \\
\hline No & 592 & $20.4(19.6,21.2)$ & 70 & $14.8(12.8,16.8)$ \\
\hline \multicolumn{5}{|l|}{ Damage severity } \\
\hline Severe & 497 & $21.2(20.3,22.1)$ & 35 & $16.5(13.2,19.8)$ \\
\hline Moderate & 277 & $18.0(16.8,19.1)$ & 43 & $15.2(12.6,17.8)$ \\
\hline No or minor & 125 & $14.1(12.5,15.7)$ & 11 & $13.9(9.0,18.8)$ \\
\hline
\end{tabular}

of patients in both age groups experiencing moderate or severe pain. In addition, while average distress scores were lower in older adults than younger adults, more than half of both older and younger adults presenting to the ED after MVC experienced substantial distress symptoms.

Persistent pain after MVC is a major public health problem and acute pain is the strongest single risk factor for persistent pain [29]. Our findings of similar acute pain scores among older and younger adults suggests that persistent pain is likely to be at least as common among older adults as among younger adults. Our finding of a mean pain score of 5.5 in the older adults is also consistent with nationally-representative data, in which $61 \%$ of older adults who were discharged after an MVCrelated ED visit had moderate or severe pain [1]. In addition, the majority of both younger and older patients 
had moderate or severe pain for each damage severity category, a finding that is consistent with prior research indicating that acute pain severity is largely independent of the severity of the collision $[29,30]$. Further studies which evaluate chronic pain outcomes and predictors of chronic pain among older adults are needed, as are studies which evaluate etiologic mechanisms of chronic pain in both groups.

Posttraumatic stress disorder (PTSD) is another common and morbid health problem resulting from MVC [31], and the initial psychological response to MVC is an important indicator of PTSD risk following MVC [32-34]. PTSD is also known to be prevalent in approximately $1 \%$ of older adults [35], and advanced age may exacerbate symptoms of PTSD [36]. In addition, the acute stress response that results from the experience of life-threat may be an important mechanism contributing to persistent post-MVC pain [37]. Although the problem of PTSD after MVC has not been described among older adults experiencing MVC, other injuries, such as falls, are known to cause PTSD in older adults [38,39]. Our results suggest that substantial distress is experienced by more than half of both older and younger adults presenting to the ED after MVC and suggest that PTSD is a problem in older adults. Interventions to treat the acute psychological response to MVC (e.g. cognitive-behavioral interventions) might be efficacious in reducing both persistent pain-related disability [40] and psychological sequelae $[41,42]$ in both age groups.

Older adults were more likely than younger adults to have an anticipated time to physical recovery or emotional recovery of 30 days or more. Patient's expectations for health outcomes are correlated with and likely influence actual health outcomes [43], and evidence from observational studies of other types of musculoskeletal pain indicates that older adults typically do require more time to recover than younger patients $[44,45]$. Thus, it seems likely that the differences in anticipated recovery times between older and younger patients in our study result largely from accurate patient assessments of the actual time that they will need to recover.

In our sample, pain catastrophizing was strongly associated with both pain severity and distress symptoms among both younger and older adults. Pain catastrophizing has previously been associated with pain severity among adults with spinal cord injury [46] and associated with pain severity and function among older adults with osteoarthritis [47]. Further, decreases in pain catastrophizing during the course of a multi-component intervention to treat chronic pain were associated with decreases in pain severity and disability [48]. Depression was also associated with pain severity and peritraumatic distress among older and younger adults in our study. Whether interventions to reduce pain catastrophizing or depression can improve pain and functional outcomes for patients presenting to the ED after MVC is unknown.

Among younger adults, those with less formal education had more pain and distress; this relationship was previously described for a subset of this cohort [49]. Increased pain and distress among less educated patients may be because these patients have less understanding of the nature of injury, less self-efficacy or more limited coping skills, or an increased burden of financial stress from MVC. The data for older adults suggest a similar inverse relationship between educational attainment and pain and distress. Further studies to better understand factors accounting for increased acute pain and distress among ED patients with lower socioeconomic status are needed.

A greater proportion of older adults than younger adults experienced moderate or severe chest pain and fewer experienced moderate or severe back or neck pain. Persistent neck, shoulder, and back pain after MVC (i.e. whiplash syndrome) is a well described phenomenon [50]. It is unclear whether acute chest pain after MVC leads to a persistent pain condition in older adults. Five of the 40 older adults in the study with moderate or severe chest pain were found to have rib or sternal fractures. The cause of chest pain in the remaining 35 patients is not known, but some likely had radiographically-occult rib fractures.

More older adults came to the ED via ambulance than younger adults. Contrary to our expectations, recent work by our group does not support the presence of a lower threshold for ambulance transport for older adults experiencing MVC [51]. Ambulance transport can be a stressful experience for patients [52], but also provides an opportunity for prehospital treatment. Prehospital care may have affected pain and distress symptoms in the study sample, but existing evidence suggests that older adults are less likely to receive analgesics than younger adults during prehospital care [53]. Further studies are needed which examine the influence of prehospital care on longitudinal pain outcomes among older adults experiencing MVC.

Prior studies have characterized outcomes after minor blunt trauma in older adults, but have included a large proportion of patients who presented to the ED after a fall [54,55]. MVCs are distinct from falls because the older adults who experience MVC are, on average, higher functioning and more likely to be living independently than patients who fall [56]. Further, our results indicate that acute pain is a substantial problem among older adults who present to the ED after MVC; acute pain is less common after a fall and when present usually results from a long bone fracture.

\section{Conclusions}

We observe that acute pain is common among older adults receiving emergency care after MVC. Further understanding of long-term outcomes after MVC among 
older adults and the factors which improve and impede the recovery process after MVC are needed to guide the initial care of this growing and vulnerable trauma population. Understanding the long-term impact of MVC on older adults also has the potential to inform the ongoing debate regarding driver safety among older adults $[57,58]$.

\section{Competing interests}

The authors declare that they have no competing interests.

\section{Authors' contributions}

GP and TPM conceived the study and supervised participant enrollment, data management, and data analysis. SM provided critical revisions for the manuscript and provided strategies to improve data presentation. $T T$ assisted with data analysis and development of the figures. JJ, DL, DP, RD, NR, and $\mathrm{PH}$ each assisted in formulating the study and questionnaire, data collection, and also provided critical feedback on the manuscript. TPM takes responsibility for the paper as a whole. All authors read and approved the final manuscript.

\section{Acknowledgments}

This study was supported by National Center for Research Resources grant KL2RR025746 and National Institute on Aging grant K32AG038548 (Dr. Platts-Mills) and National Institute of Arthritis and Musculoskeletal and Skin Diseases grant R01AR056428 (Dr. McLean). We thank the study participants for making the study possible, and Katherine Hunold, and Erin Isenberg for their contributions to data collection.

\section{Author details}

${ }^{1}$ School of Medicine, University of Pennsylvania, Philadelphia, PA, USA ${ }^{2}$ Department of Anesthesiology, University of North Carolina, 101 Manning Drive, CB \#7010, Chapel Hill, NC 27599-7010, USA. ${ }^{3}$ Departments of Emergency Medicine and Anesthesiology, University of North Carolina, 101 Manning Drive, CB \#7010, Chapel Hill, NC 27599-7010, USA. 'Department of Emergency Medicine, William Beaumont Hospital, Royal Oak, MI, USA. ${ }^{5}$ Department of Emergency Medicine, Spectrum Health - Butterworth Campus, Grand Rapids, MI, USA. ${ }^{6}$ Department of Emergency Medicine, North Shore University Hospital, Manhasset, NY, USA. ${ }^{7}$ Department of Emergency Medicine, Massachusetts General Hospital, Boston, MA, USA. ${ }^{8}$ Department of Emergency Medicine, St. Joseph Mercy Hospital, Ann Arbor, MI, USA. ${ }^{9}$ Department of Emergency Medicine, Baystate Medical Center, Springfield, MA, USA. ${ }^{10}$ Department of Emergency Medicine and Pediatrics, University of Florida-Jacksonville, Jacksonville, FL, USA.

Received: 6 September 2013 Accepted: 9 December 2014 Published online: 30 December 2014

\section{References}

1. Platts-Mills TF, Hunold KM, Esserman DA, Sloane PD, McLean SA: Motor vehicle collision-related emergency department visits by older adults in the United States. Acad Emerg Med 2012, 19:821-827.

2. Dellinger AM, Stevens JA: The injury problem among older adults: mortality, morbidity and costs. J Saf Res 2006, 37:519-522.

3. Lyman S, Ferguson SA, Braver ER, Williams AF: Older driver involvements in police reported crashes and fatal crashes: trends and projections. Inj Prev: J Int Soc Child Adolesc Inj Prev 2002, 8:116-120,

4. Lien YC, Chen CH, Lin HC: Risk factors for 24-hour mortality after traumatic rib fractures owing to motor vehicle accidents: a nationwide population-based study. Ann Thorac Surg 2009, 88:1124-1130.

5. Bergeron E, Lavoie A, Clas D, Moore L, Ratte S, Tetreault S, Lemaire J, Martin M: Elderly trauma patients with rib fractures are at greater risk of death and pneumonia. J Trauma 2003, 54:478-485.

6. Taylor MD, Tracy JK, Meyer W, Pasquale M, Napolitano LM: Trauma in the elderly: intensive care unit resource use and outcome. J Trauma 2002, 53:407-414.

7. Wojtusik L, White MC: Health status, needs, and health care barriers among the homeless. J Health Care Poor Underserved 1998, 9:140-152.

8. Soothill K, Morris SM, Harman J, Francis B, Thomas C, Mclllmurray MB: The significant unmet needs of cancer patients: probing psychosocial concerns. Support Care Canc: Offic J Multinational Assoc Support Care Canc 2001, 9:597-605.
9. Mitus AJ: The birth of InterQual: evidence-based decision support criteria that helped change healthcare. Prof Case Manag 2008, 13:228-233.

10. American Health Care Association. What is OSCAR Data? (Accessed August 26, 2013, at http://www.ahcancal.org/research_data/oscar_data/Pages/ WhatisOSCARData.aspx).

11. Holm LW, Carroll $\amalg$, Cassidy JD, Hogg-Johnson S, Cote P, Guzman J, Peloso P, Nordin M, Hurwitz E, van der Velde G, Carragee E, Haldeman S: The burden and determinants of neck pain in whiplash-associated disorders after traffic collisions: results of the bone and joint decade 2000-2010 task force on neck pain and its associated disorders. Spine (Phila Pa 1976) 2008, 33:S52-S59.

12. Holbrook TL, Galarneau MR, Dye JL, Quinn K, Dougherty AL: Morphine use after combat injury in Iraq and post-traumatic stress disorder. N Engl J Med 2010, 362:110-117.

13. Brison RJ, Hartling L, Dostaler S, Leger A, Rowe BH, Stiell I, Pickett W: A randomized controlled trial of an educational intervention to prevent the chronic pain of whiplash associated disorders following rear-end motor vehicle collisions. Spine 2005, 30:1799-1807.

14. Platts-Mills TF, Ballina L, Bortsov AV, Soward A, Swor RA, Jones JS, Lee DC, Peak DA, Domeier RM, Rathlev NK, Hendry PL, McLean SA: Using emergency department-based inception cohorts to determine genetic characteristics associated with long term patient outcomes after motor vehicle collision: methodology of the CRASH study. BMC Emerg Med 2011, 11:14.

15. Diatchenko L, Slade GD, Nackley AG, Maixner W: Responses to Drs. Kim and Dionne regarding comments on Diatchenko, et al. Catechol-Omethyltransferase gene polymorphisms are associated with multiple pain-evoking stimuli. Pain 2006, 125:216-224. Pain 2007;129:366-70

16. Callahan CM, Unverzagt FW, Hui SL, Perkins AJ, Hendrie HC: Six-item screener to identify cognitive impairment among potential subjects for clinical research. Med Care 2002, 40:771-781.

17. Lee YM, Platts-Mills TF, MacWilliams JB, Sochor MR, Jones JS, Schneider LW McLean SA: Descriptions of motor vehicle collisions by participants in Emergency Department-based studies: are they accurate? West J Emerg Med 2012, 13:329-34.

18. Brunet A, Weiss DS, Metzler TJ, Best SR, Neylan TC, Rogers C, Fagan J, Marmar CR: The peritraumatic distress inventory: a proposed measure of PTSD criterion A2. Am J Psychiatry 2001, 158:1480-1485.

19. Sullivan MJ, Bishop S, Pivik J: The pain catastrophizing scale: development and validation. Psychol Assess 1995, 7:524-532.

20. Radloff LS: The CES-D Scale: a self-report depression scale for research in the general population. Appl Psychol Meas 1977, 1:385-401.

21. Andresen EM, Malmgren JA, Carter WB, Patrick DL: Screening for depression in well older adults: evaluation of a short form of the CES-D (Center for Epidemiologic Studies Depression Scale). Am J Prev Med 1994, 10:77-84.

22. Smulowitz PB, Lipton R, Wharam JF, Adelman L, Weiner SG, Burke L, Baugh CW, Schuur JD, Liu SW, McGrath ME, Liu B, Sayah A, Burke MC, Pope JH, Landon BE: Emergency department utilization after the implementation of Massachusetts health reform. Ann Emerg Med 2011, 58:225-234. e1.

23. Weber EJ, Showstack JA, Hunt KA, Colby DC, Grimes B, Bacchetti P, Callaham $M L$ : Are the uninsured responsible for the increase in emergency department visits in the United States? Ann Emerg Med 2008, 52:108-115.

24. Nishi D, Koido Y, Nakaya N, Sone T, Noguchi H, Hamazaki K, Hamazaki T, Matsuoka Y: Peritraumatic distress, watching television, and posttraumatic stress symptoms among rescue workers after the Great East Japan earthquake. PLoS One 2012, 7:e35248.

25. Wenger NS, Pearson ML, Desmond KA, Harrison ER, Rubenstein LV, Rogers WH, Kahn KL: Epidemiology of do-not-resuscitate orders. Disparity by age, diagnosis, gender, race, and functional impairment. Arch Intern Med 1995, 155:2056-2062.

26. Helmkamp JC, Carter MW: ATV deaths among older adults in West Virginia: evidence suggesting that "60 is the new 40!". South Med J 2009, 102:465-469.

27. Ekman R, Welander G, Svanstrom L, Schelp L, Santesson P: Bicycle-related injuries among the elderly-a new epidemic? Publ Health 2001, 115:38-43.

28. Block L, Ma S, Emerson M, Langley A, Torre Dde L, Noronha G: Does access to comprehensive outpatient care alter patterns of emergency department utilization among uninsured patients in East Baltimore? J Prim Care Community Health 2013, 4:143-147.

29. Sterling M, Hendrikz J, Kenardy J: Similar factors predict disability and posttraumatic stress disorder trajectories after whiplash injury. Pain 2011, 152:1272-1278.

30. Bortsov AV, Platts-Mills TF, Peak DA, Jones JS, Swor RA, Domeier RM, Lee DC, Rathlev NK, Hendry PL, Fillingim RB, McLean SA: Pain distribution and 
predictors of widespread pain in the immediate aftermath of motor vehicle collision. Eur J Pain 2013, 17:1243-1251.

31. Wu KK, Cheung MW: Posttraumatic stress after a motor vehicle accident a six-month follow-up study utilizing latent growth modeling. J Trauma Stress 2006, 19:923-936.

32. Scudds RJ, Ostbye T: Pain and pain-related interference with function in older Canadians: the Canadian Study of Health and Aging. Disabil Rehabil 2001, 23:654-664

33. Morley S, Eccleston C, Williams A: Systematic review and meta-analysis of randomized controlled trials of cognitive behaviour therapy and behaviour therapy for chronic pain in adults, excluding headache. Pain 1999, 80:1-13.

34. Yasan A, Guzel A, Tamam Y, Ozkan M: Predictive factors for acute stress disorder and posttraumatic stress disorder after motor vehicle accidents. Psychopathology 2009, 42:236-241.

35. van Zelst WH, de Beurs E, Beekman AT, Deeg DJ, van Dyck R: Prevalence and risk factors of posttraumatic stress disorder in older adults. Psychother Psychosom 2003, 72:333-342.

36. Macleod AD: The reactivation of post-traumatic stress disorder in later life. Aust N Z J Psychiatry 1994, 28:625-634.

37. McLean SA, Clauw DJ, Abelson JL, Liberzon I: The development of persistent pain and psychological morbidity after motor vehicle collision: integrating the potential role of stress response systems into a biopsychosocial model. Psychosom Med 2005, 67:783-790.

38. Bloch F, Blandin M, Ranerison R, Claessens YE, Rigaud AS, Kemoun G: Anxiety after a fall in elderly subjects and subsequent risk of developing post traumatic stress disorder at two months. A pilot study. J Nutr Health Aging 2014, 18:303-306.

39. Chung MC, McKee KJ, Austin C, Barkby H, Brown H, Cash S, Ellingford J, Hanger L, Pais T: Posttraumatic stress disorder in older people after a fall. Int J Geriatr Psychiatry 2009, 24:955-964.

40. Dunne RL, Kenardy J, Sterling M: A randomized controlled trial of cognitive-behavioral therapy for the treatment of PTSD in the context of chronic whiplash. Clin J Pain 2012, 28:755-765.

41. Centers for Disease Control and Prevention: Guidelines for Field Triage of Injured Patients, Morbidity and Mortality Weekly Report. ; 2012:61.

42. O'Donnell ML, Lau W, Tipping S, Holmes AC, Ellen S, Judson R, Varker T, Elliot P, Bryant RA, Creamer MC, Forbes D: Stepped early psychological intervention for posttraumatic stress disorder, other anxiety disorders, and depression following serious injury. J Trauma Stress 2012, 25:125-133.

43. Lamantia MA, Stewart PW, Platts-Mills TF, Biese KJ, Forbach C, Zamora E, McCall BK, Shofer FS, Cairns CB, Busby-Whitehead J, Kizer JS: Predictive value of initial triage vital signs for critically III older adults. Western J Emerg Med 2013, 14:453-460.

44. Henschke N, Maher CG, Refshauge KM, Herbert RD, Cumming RG, Bleasel J, York J, Das A, McAuley JH: Prognosis in patients with recent onset low back pain in Australian primary care: inception cohort study. BMJ 2008, 337:a171

45. Grotle M, Brox Jl, Veierod MB, Glomsrod B, Lonn JH, Vollestad NK: Clinical course and prognostic factors in acute low back pain: patients consulting primary care for the first time. Spine 2005, 30:976-982.

46. Turner JA, Jensen MP, Warms CA, Cardenas DD: Catastrophizing is associated with pain intensity, psychological distress, and pain-related disability among individuals with chronic pain after spinal cord injury. Pain 2002, 98:127-134

47. Keefe FJ, Lefebvre JC, Egert JR, Affleck G, Sullivan MJ, Caldwell DS: The relationship of gender to pain, pain behavior, and disability in osteoarthritis patients: the role of catastrophizing. Pain 2000, 87:325-334.

48. Jensen MP, Turner JA, Romano JM: Changes in beliefs, catastrophizing, and coping are associated with improvement in multidisciplinary pain treatment. J Consult Clin Psychol 2001, 69:655-662.

49. Hatley T, Patterson PD: Management and financing of emergency medical services. N C Med J 2007, 68:259-261.

50. Hincapie CA, Cassidy JD, Cote P, Carroll LJ, Guzman J: Whiplash injury is more than neck pain: a population-based study of pain localization after traffic injury. J Occup Environ Med 2010, 52:434-440.

51. Hunold KM, Sochor MR, McLean SA, Mosteller KB, Fernandez AR, Platts-Mills TF: Ambulance transport rates after motor vehicle collision for older vs. younger adults: A population-based study. Accid Anal Prev 2014, 73C:373-379.

52. Dorges V, Wenzel V, Kuhl A, Dix S, Huppe M, Gehring H, Schumann T, Gerlach K Emergency medical service transport-induced stress? An experimental approach with healthy volunteers. Resuscitation 2001, 49:151-157.
53. Platts-Mills TF, Hunold KM, Weaver MA, Dickey RM, Fernandez AR, Fillingim RB, Cairns CB, McLean SA: Pain treatment for older adults during prehospital emergency care: variations by patient gender and pain severity. J Pain 2013, 14:966-974.

54. Wilber ST, Blanda M, Gerson LW, Allen KR: Short-term functional decline and service use in older emergency department patients with blunt injuries. Acad Emerg Med: Offic J Soc Acad Emerg Med 2010, 17:679-686.

55. Shapiro MJ, Partridge RA, Jenouri I, Micalone M, Gifford D: Functional decline in independent elders after minor traumatic injury. Acad Emerg Med: Offic J Soc Acad Emerg Med 2001, 8:78-81.

56. Bell AJ, Talbot-Stern JK, Hennessy A: Characteristics and outcomes of older patients presenting to the emergency department after a fall: a retrospective analysis. Med J Aust 2000, 173:179-182.

57. Betz ME, Lowenstein SR: Driving patterns of older adults: results from the Second Injury Control and Risk Survey. J Am Geriatr Soc 2010, 58:1931-1935.

58. Betz ME, Schwartz R, Haukoos JS, DiGuiseppi C, Valley M, Johnson R, Lowenstein SR: A pilot study to develop a brief question-based screening tool to identify higher-risk older drivers. J Am Geriatr Soc 2012, 60:1791-1794.

\section{Submit your next manuscript to BioMed Central and take full advantage of:}

- Convenient online submission

- Thorough peer review

- No space constraints or color figure charges

- Immediate publication on acceptance

- Inclusion in PubMed, CAS, Scopus and Google Scholar

- Research which is freely available for redistribution

Submit your manuscript at www.biomedcentral.com/submit
C BioMed Central 